\section{Três notas sobre a relação entre filosofia e forma textual nos Ensaios de Bacon*}

\section{Homero Santiago**}

Resumo: Nosso propósito é tratar dos Ensaios de Francis Bacon e de sua significação filosófica a partir da consideração de alguns aspectos de sua forma textual: o inacabamento da obra, a variação de seus fins, suas construções classificatórias. Embora à primeira vista tais características possam sugerir uma fraqueza teórica, em verdade exprimem a formação de um novo ideal de filosofia.

Palavras-chave: Bacon, Ensaios, Forma filosófica.

Nosso propósito é tratar dos Ensaios de Francis Bacon e de sua significação filosófica, pensando-os em estreito vínculo com o restante da obra baconiana. Trata-se do primeiro trabalho do filósofo e, embora bastante modificado ao longo dos anos por acréscimos e rearranjos, quer-nos parecer que ele oferece desde a primeira edição alguns traços que vão persistir e lhe garantir um caráter invariante. Ora, que tipo de filosofia responde por traços do projeto baconiano dos Ensaios e, portanto, é anunciada por eles?

Para tentar dar conta disso, ainda que parcialmente, vamos nos deter no que pode ser entendido como a forma do livro e alguns aspectos de sua elaboração. À primeira vista, os Ensaios, como quase todas as obras de Bacon, apresentam uma série de deficiências que podem funcionar como síntese de certas dificuldades que afligiriam a filosofia baconiana no plano da forma. ${ }^{1}$ Dado isso, a questão que se põe é: será que tais traços, em vez de defeitos, não poderiam ser considerados qualidades? Desde que ponhamos o acento sobre o esforço baconiano em produzir uma nova imagem da filosofia diversa daquela tradicional e presente desde os gregos, os próprios critérios de avaliação não devem mudar e o que poderia ser deficiência à luz da sabedoria tradicional tornar-se, pelo contrário, qualidade do ponto de vista da filosofia baconiana?

As três notas que se seguem buscam responder a essa indagações.

\footnotetext{
* Texto apresentado no Colóquio Humanismo do Renascimento, Departamento de Filosofia - USP, agosto de 2007.

** Professor do Departamento de Filosofia da USP.
}

\section{Composição e inacabamento}

A composição dos Ensaios prolonga-se por toda a vida de Bacon; a obra conhece três edições sempre diferentes: a primeira, de 1597, traz 10 ensaios; a segunda, de 1612, 38 ensaios; a terceira, por fim, de 1625, contém 58 ensaios. O longo processo de elaboração, que podemos acompanhar com certo detalhe ${ }^{2}$, deixou suas marcas na obra: variação nos temas, no estilo, na estrutura textual, nos pontos de vista que vão dos do jovem que dá seus primeiros passos aos do velho calejado nos negócios do mundo; contínua revisão dos textos antigos e inserção de novos materiais, quer citações (aparentemente, conforme o filósofo vai lendo coisas novas daí retira frases e exemplos), quer trechos inteiros (alguns significativamente derivados das novas condições de vida, da carreira de Bacon, de novos acontecimentos). ${ }^{3}$ Os vários aspectos dessa transformação dos Ensaios no correr dos anos, seu processo peculiar de composição, talvez possam nos instruir sobre o que denominaríamos o modelo de obra baconiana ou, ao menos, acerca de uma característica a nosso ver capital do processo compositivo de todas as obras baconianas: o inacabamento necessário.

A primeira idéia que nós fazemos de uma obra dita "inacabada" é que ela não foi terminada (as razões podendo variar desde o abandono puro e simples até morte do autor). Não é esse, porém, o inacabamento que podemos assinalar aos Ensaios. Muito pelo contrário. Se cabe falar em inacabamento, este não se deve ao abandono, mas ao trabalho contínuo sobre o material; não se deve à morte, mas antes a uma vida que se transforma com intensidade. O inacabamento dos Ensaios é marcado pelas revisões, pelas inserções; o texto muda com as mudanças na própria pessoa do autor, com os fatos e os cargos, com os estudos; acréscimos vão sendo feitos numa medida tal que, como sugerem alguns fragmentos, caso se alongasse a existência do filósofo, novos ensaios apareceriam. ${ }^{4}$

Isso tudo pode ser afirmado dos Ensaios com certa segurança, uma vez que seu curso e suas alterações ao longo do tempo podem ser em grande parte reconstituídos; mas não seria o mesmo inacabamento uma característica generalizável, pertinente a todas as obras baconianas? Ora, gostaríamos de avançar a suposição de que praticamente todos os textos de Bacon conhecem inacabamento semelhante, não só os inéditos como também os publicados. Justificativas para a hipótese não são difíceis. Basta observar que todos os 
temas do Avanço do saber, de 1605, são retomados e sobretudo expandidos ao longo dos anos e principalmente na versão latina, o De augmentis scientiarum, de 1623. O volume sobre a Sabedoria dos antigos, de 1609, deve ser encarado menos como um trabalho terminado que um momento, apenas cristalizado pela publicação, de uma ininterrupta atividade de interpretação alegórica dos mitos e fábulas antigos sempre praticada por Bacon, como o demonstram os sinais esparsos no Do avanço do saber e as novas interpretações surgidas no De augmentis. Por fim, exemplo incontornável, é o volume da Grande instauração, vindo a lume em 1620, é um caso acabado de obra inacabada, se o leitor permite, a que o autor dedica quase 30 anos (ver carta ao rei, 12-10-1620, Bacon 4, v. XIV, p. 120). Encontramos ali o rearranjo de praticamente tudo que o filósofo escreveu até 1620; para nem citar outros fatores, paradigmática é a combinação de quase todos os estilos até então tentados: a segunda pessoa (a epístola dedicatória ou o Do avanço do saber, dirigido diretamente ao rei), a terceira pessoa (seja na inserção de um terceiro, como na Redargutio philosophiarum, seja no tratamento do próprio eu como um terceiro: F.B. sic cogitavit), o aforismo, o discurso aos filhos (como no Temporis partus masculus) etc.

Talvez muito do que alguns estudiosos identificam como mal ajambramento dos textos baconianos - às vezes com certa razão - seja reflexo desse inacabamento necessário de uma obra sempre a ser feita, o que, por sua vez, pensamos, remete a uma dificuldade filosófica que o próprio lorde chanceler não deixou de tocar numa carta de 1610: "nada está acabado até que tudo esteja acabado" (a Sir Tobie Matthew, apud Melchionda 9, p. 32). Qual será o significado dessa confissão? Primeiramente, a certeza da amplitude de um projeto como o de nenhum outro homem, nada mais, nada menos que restaurar a condição adâmica (Bacon 1, II, 52); depois, ver-se forçado a um trabalho quiçá infinito, como exprimido nas promessas de obras, nas várias histórias planejadas, na ênfase no que está por fazer mais do que no já feito. Justamente, daí vem o inacabamento essencial daquilo que está sempre em andamento e que é, por isso, essencialmente sem fim. Cada obra de Bacon publicada é momento cristalizado de um processo, mas apenas para ser logo retocado, revisto, aumentado, redirecionado. Isso não é exclusividade dos Ensaios, como já dito, eles somente nos permitem, por sua trajetória peculiar (várias edições, manuscritos etc.), apreendê-lo mais claramente; eles não padecem de gratuidade, antes são expressão de um pensamento que dialoga incessantemente com a vida, com o mundo e que jamais se aquieta, reservando apenas injúrias aos que sonham com a perenidade. Se há ponto final, este vem só com a morte do autor, pois a obra é também uma vida. ${ }^{5}$

Arriscaria dizer que o que Bacon descobre no trabalho com seu texto (o que não quer dizer que ele se dê conta disso) é o inacabamento necessário de toda obra; um pouco como a literatura moderna descobrirá a obra sempre inacabada, um universo sempre em expansão - tenhamos em mente Em busca do tempo perdido: conhecemos o fim da obra, nada porém nos garante que deveria ser assim; o final da obra (tanto na forma quanto no conteúdo) corresponde ao fim da vida do autor, sendo apenas "o último estado de uma escrita interrompida" (Robert 10, p.61). A obra é o produto de toda a vida, anotações, esboços, versões; de uma vida dedicada à redação de uma única obra (e vem ao caso perguntar se ao longo de toda sua vida Bacon não buscou redigir, também ele, uma única obra: a instauratio magna — é o que pensamos).

Pode parecer um tanto abusivo e deslocado, cabe reconhecer, e por isso mesmo não deixamos de usar o verbo "arriscar". De qualquer modo, gostaríamos ainda de reforçar o ponto de vista, observando que tal inacabamento essencial que descobrimos na composição dos Ensaios encontra, parece-nos, correspondência nas concepções teóricas de Bacon. A obra essencialmente inacabada é uma obra sem fim, sempre em progresso; e é este progresso - verdadeira chave da filosofia baconiana - que no final das contas determina o inacabamento.

Tomemos o ensaio "Dos estudos", que abria a primeira edição. Os estudos, afirma-se, "aperfeiçoam a natureza e são aperfeiçoados pela experiência, porque os talentos naturais são como plantas naturais, por necessidade, podadas pelos estudos; e estudos em si só dão orientações gerais, a menos que afiados pela experiência.” O vínculo estabelecido entre estudo e experiência nos permite derivar uma situação peculiar: o estudo aumenta, cresce conforme o tempo, por isso é natural que o fruto do estudo (a obra) se transforme com o tempo, incessantemente. É uma idéia ainda incipiente, pouco clara no ensaio, mas intuição de grande futuro na madureza de Bacon, especialmente na renovada concepção de lógica apresentada no Novo órganon.

A lógica é instrumento do intelecto como o martelo é instrumento das mãos, 
e ambos podem progredir. Eis um dos traços mais fascinantes da filosofia baconiana. A lógica tradicional trata do que é necessário, universal e eterno; pode assim enunciar regras do pensamento correto que não admitem progresso nenhum — como observará Kant ao abrir a Crítica da razão pura, no essencial, a lógica desde Aristóteles nunca deu "um passo atrás", e ainda mais digno de nota é que "não conseguiu dar um passo adiante e, por conseguinte, segundo todos os indícios, parece estar concluída e acabada" (Kant 7, p. 28). É contra esse tipo de acabamento que se ergue a lógica baconiana. Na medida em que nos reconduz às coisas e faz nossas noções comungarem com elas, podendo mesmo ser dita uma lógica do real ou concreta, a nova lógica baconiana se abre para o novo e renega a perenidade; é uma lógica histórica, pois pode e deve progredir conforme mudam nossas relações com as coisas, a maior ou menor amplidão do mundo a que nos lançamos. Se antes os estudos comungavam com a experiência numa relação de recíproca implicação, no Novo órganon, com mais clareza, são a mente e as coisas que estão nessa relação. Leiamos o final do aforismo I, 130: "nós que consideramos a mente não só nas suas faculdades, mas na sua união com as coisas, devemos afirmar que a arte de descobrir pode crescer com o crescer das descobertas." (Bacon 1; grifos nossos) Assim, por exemplo, a descoberta do Novo Mundo pode determinar um novo patamar para o pensamento: não se pensa da mesma forma antes e depois da América, e a lógica deve transformar-se. Ou seja, também ela pode ser dita inacabável, pois falamos de um processo também ele inacabável.

Em conclusão, a verdadeira obra de pensamento é essencialmente inacabada porque o pensamento se transforma, cresce conforme as suas condições (a descoberta da América, as experiências, os cargos, os conhecimentos etc.) e, principalmente, muda seus objetivos, seus fins. É destes que, agora, queremos tratar.

\section{Os objetivos da obra}

Cada homem tem suas questões, suas ambições, e ao preparar uma obra é natural que tais questões e ambições determinem certos objetivos à obra. Porém, sendo tal obra necessariamente inacabada, de forma que sua composição estenda-se pela vida do autor, não é menos natural que as questões, os problemas, os objetivos que a animam passem por mudanças; no limite, cada fase da vida de um homem tem seus problemas, suas ambições, e estes podem determinar objetivos diferentes, a cada momento, para suas obras - algo que se pode refletir até em pormenores. ${ }^{6}$ É claro que isso pode dar a impressão de certa fraqueza de um pensamento que simplesmente padeceria de incessante variação, vítima das modas, das intempéries; uma espécie de raciocínio que não se demora antes de ajuizar. É verdade, mas temos de convir que, se há aí uma debilidade, pode-se igualmente reconhecer uma força tanto maior, expressa na tese baconiana, cedo exposta, de que ofim do saber nunca é ele próprio. A consideração desse ponto nos ajuda a entender as variações dos Ensaios, ao longo de seu curso, também como uma variação dos fins que lhe são assinalados; noutros termos, uma resposta diferente à interrogação: para quê serve isso?

Tomemos ainda o mesmo exemplo antigo do ensaio "Dos estudos". O texto se abre tratando da serventia dos estudos, a partir de uma classificação: servem para o deleite, para o ornamento, para os negócios. Neste último caso, identificamos dois tipos de pessoas que se servem dos estudos para os negócios e entre eles se estabelece uma contraposição: o especialista (expert) e o instruído (learned). O primeiro é aquele que ajuíza o particular, é dotado de certo pontilhismo que descamba para o pedantismo, possui o "humor de um escolástico (scholler)"; o instruído, diferentemente, para lá da particularidade trata das "deliberações (counsels) gerais, e os planos e organização de negócios"; é aquele que, podemos dizer, sabe conferir um fim, uma direção, aos próprios estudos. Com efeito, a tese fundamental de todo o ensaio é que os estudos não trazem em si o seu próprio fim, portanto é preciso dirigi-lo.

Acompanhemos esta nova classificação: "homens audaciosos desprezam os estudos, os homens simples os admiram e os sábios (wise men) os usam, porque não ensinam seu próprio uso; mas há uma sabedoria (wisdome) sem eles, e acima deles, ganha na observação." Os estudos não são o fim último de nada, muito menos constituem um fim em si mesmos. Sábio (e podemos assimilar-lhe aqui o instruído) é aquele justamente que, de posse de uma sabedoria que independe dos estudos, sabe aplicá-la a estes conferindolhes uma direção; aquele que em vez de desprezar ou admirar-se sabe servir-se dos estudos, e para isso impõe-lhes um fim, uma utilidade.

No caso do próprio ensaio, a utilidade imediata, a serventia do estudo é 
a transformação de si próprio, certa arquitetura de si: "os estudos moldam o caráter" (abeunt studia in mores) — tese igualmente presente no Do avanço do saber (Bacon 2, p. 38). Como eles são capazes de tanto, é preciso saber usá-los, direcioná-los para o que se quer. E sabiamente, porque aí - como em tudo o mais - caminha-se para o sucesso ou para a ruína. Não por acaso, o "Dos estudos" nos sugerem que, aplicados aos negócios, os estudos e a sabedoria tomam por critério o êxito, pois “o que é falso em sabedoria é a ruína de negócios". Ora, não podemos senão apreciar a longevidade desse ponto de vista de 1597 que atravessa a obra de Bacon e ganhará a forma de um enunciado tético claríssimo: os frutos são garantia da verdade das filosofias; a mesma coisa é a verdade e a utilidade; o que é útil no operar, é verdadeiro no saber (Bacon 1, I, 73, 121; II, 4).

Tomados os Ensaios sob essa perspectiva, muitas das mudanças de tema e tratamento, as várias dedicatórias, tornam-se compreensíveis e, sobretudo, conseqüentes. Como mostram as análises de Michel Kiernan, de maneira muito convincente, não se deve conceber o trabalho à guisa de mera contribuição à psicologia e à arte política ou então espelho da classe dominante da época. Antes, eles respondem a certas inquietações próprias de seu autor, a sua condição, as quais mudam com o passar do tempo, e levam os Ensaios, a reboque, a também mudar.

Os 10 ensaios mais antigos, da primeira edição, exprimem o ponto de vista de um "pretendente" (suitor), de alguém que quer e persegue um poder que ainda não tem; a obra surge então como uma espécie de vademécum do homem ambicioso. Bacon ensina a não questionar muito ou saber quando e como perguntar, a calar sobre si a menos que seja oportuno ("Do discurso"), ensina quando ser cerimonioso ("De cerimônias e homenagens"), e assim por diante (cf. Kiernan 8, p. XX e seg.). Na primeira edição dos Ensaios, impera o ponto de vista de alguém que está de fora do poder, em contraste patente com os ensaios da segunda edição, próprios de alguém que já está dentro, que teve acesso ao poder, e os da terceira, que não por acaso vão ganhar um subtítulo: Ensaios ou conselhos civis e morais. Com o processo de 1621, caído em desgraça, impedido de assumir cargos públicos, Bacon tenta de tudo para ser admitido como conselheiro, aquele que pode dar direção aos poderosos oferecendo-lhes um saber adquirido pela experiência e que não se encontra nos livros. É uma hipótese que ganha força por uma carta enviada pelo filósofo ao embaixador espanhol dois meses após o processo que sofreu: Bacon anuncia sua intenção de continuar como conselheiro, mas agora com a pena; vai retirar-se do teatro das coisas civis e dedicar-se às letras, como alguém que quer "instruir os atores" e assim servir à posteridade (cf. Bacon 4, v. XIV, p. 285).

Aqui, novamente, os Ensaios vêm ilustrar à perfeição uma tese fundamental de Bacon e recobrir de coerência o que, a olhos apressados, poderia sugerir indecisão dos objetivos. A obra exprime um saber voltado para um fim que não é o próprio saber; nela o saber ganha uma utilidade, está em busca de um poder e esforça-se mesmo por coincidir com ele, na medida em que possa responder às ambições do sábio. No plano moral ou ético, tem-se a mesma expressão daquilo que a grande instauração vai afirmar, noutro plano, como a identidade entre o saber e a potência. Apreciamos um saber que tenta coincidir com um poder de transformar-se: o conhecimento é um conhecimento de si e esse si está em busca de êxito; saber de um si em expansão, que quer e busca alcançar o que quer sabendo guiar-se. A pura contemplação deve então tornar-se uma "contemplação ativa", ou seja, um saber transformador, um saber próprio para a vida ativa e que possa responder aos anseios e desejos humanos. Trata-se de impor-se um objetivo e alcançá-lo, pois, como dissera Sêneca, "a vida sem um propósito é lânguida e errante, vaga" (vita sine proposito languida et vaga est); e nosso filósofo acrescenta que é "com prazer" que, nas empresas, ocupações e propósitos da vida, os observamos "em seus começos, progressos, retrocessos, renovações, aproximações e consecuções” (Bacon 2, p. 237).

A partir disso, é cabível ainda nos perguntarmos seriamente: todo o projeto de grande instauração não busca realizar o mesmo, só que tomando sob o mencionado "si” a humanidade em vez de um indivíduo? Cremos que sim. ${ }^{7}$ Os Ensaios não surgem como peça ocasional, mas exemplar de uma nova concepção de filosofia que se afasta da canônica (filosofia $=$ contemplação $=$ fim em si) na medida que se oferece ao homem como instrutora no combate que é o da existência, concedendo-lhe armas, orientando-lhe por caminhos incertos e perigosos sempre em direção à realização de seus desejos. ${ }^{8}$

\section{A frase classificatória}

No que se refere à estrutura argumentativa dos Ensaios, vamos de textos curtos que têm a aparência de mera conexão de frases (lembremos o quanto Bacon gostava de 
recolher máximas, aforismos, apotegmas), nem sempre com transição lógica clara, até textos mais alongados e que apresentam uma estruturação firme; nos dois casos, é comum a abertura (um ditado, uma citação, um enunciado geral) assumir um papel determinante ao fornecer o foco a partir do qual o ensaio se desdobra. De qualquer modo, o componente básico do texto é quase sempre um tipo particular de frase que denominaríamos a frase classificatória. A presença ostensiva dessa fraseologia é uma característica marcante do livro: tudo é catalogado, dividido em graus, tem seus resultados analisados. Por exemplo: "Há três graus com que se oculta e veda o íntimo de um homem. O primeiro, silêncio, reserva e segredo... O segundo, dissimulação... O terceiro, a simulação...” (“Da simulação e dissimulação"). No ensaio "Da amizade", classificação e análise dos frutos da amizade: 1) desabafo, 2) relacionar-se, ajuda na compreensão; 3) o amigo continua o que não fizemos. As ilustrações poderiam ser numerosas, já que parte substantiva da obra, da primeira à última edição, serve-se do mesmo expediente.

$\mathrm{O}$ arranjo, ao que parece, tende a dar má impressão nos leitores e chegou a merecer críticas severas, que não pouparam sequer o caráter do filósofo. "Bacon aparece antes de tudo preocupado em fazer distinções judiciosas, reduzir a matéria em classificações nítidas. (...) Esses perpétuos cálculos, essas receitas demasiado engenhosas, dão a impressão de um homem que não nasceu para a ação, que se fez da humanidade uma concepção teórica e livresca, que medita e vigia seus menores gestos (...). Assim, a variedade da vida, a diversidade dos homens, não lhe inspiram senão uma curiosidade secamente intelectual; ele as considera friamente como um sábio que examina plantas ou insetos, e os classifica em seu catálogo" (Castelain 5, p. XXXVIII e seg.).

Porventura seja verdade que os Ensaios deixam a impressão de certa mania classificatória e calculista (que para piorar é associada por Bacon, no próprio livro, ao espírito escolástico). Porém, devemos desconfiar que o exercício tenha um significado maior, distante da mera idiossincrasia. Primeiro, ele permanece nas outras obras, notadamente no Novo órganon (gêneros de filósofos, de ídolos, de esperanças, classificação extensa de prerrogativas etc.), e funciona como o resultado de uma grande perscrutação do mundo, um grande exercício histórico que dá o substrato do pensamento. Segundo, e mais importante, esses cálculos classificatórios dos Ensaios são o exato oposto do exercício contemplativo; o filósofo ali nunca cede à admiração que deixa em estagnação; a filosofia não nasce da admiração (coisa de "pessoas simples", como dá a entender o "Dos estudos"), mas da ambição. O cálculo e a classificação merecem ser compreendidos como resultado da meticulosidade; uma observação meticulosa que põe em movimento o sujeito dotando-lhe de armas, de estratégias. Àquele, por exemplo, que persegue um poder, como Bacon nos primeiros ensaios, o saber bem direcionado pode tornar-se uma arma valiosa, a orientar os seus passos. Tal meticulosidade é um método — termo que em sua amplitude encontra sentido tanto no plano individual quanto nas empresas científicas, pois nada nos sugere cogitar uma descontinuidade entre a instauração de uma nova vida e a grande instauração de uma nova humanidade. As classificações têm para o pensamento ético um papel semelhante ao da história natural para a lógica, ou seja, de fundamento.

Nesse sentido, o tradutor francês teria razão na análise da atitude baconiana; peca apenas ao ajuizar o valor dessa atitude. A frase classificatória, entendida como expressão de meticulosidade analítica, está longe de revelar incapacidade para a ação; é bem o contrário, ela exprime um saber que descobriu sua coincidência necessária com a ação e que deve unir a via contemplativa e a via ativa, aprender com as coisas, sob o risco da irrelevância. Não se há de negar certa secura e frieza desse saber, mas tampouco se poderão negar os trunfos que ele traz, sobretudo na capacidade de discernimento. É precisamente tal saber que responde por alguns dos melhores momentos dos Ensaios, por uma argúcia incomparável, sobretudo quando o autor se volta para a análise de certos assuntos inusitados e, pelo menos em aparência, irrelevantes. Assim, no ensaio "De jardins" poderíamos esperar uma contemplação respeitosa e sábia da magnitude da natureza; o que encontramos, todavia, é a observação meticulosa de como deve ser o jardim de um monarca, que plantas deve conter, o que significa cada uma; ou seja, a compreensão exata de que o jardim de um rei pode ser o próprio espelho de seu poder, o seu domínio em exercício. O mesmo ocorre num dos mais saborosos e instigantes ensaios do livro, intitulado "De mascaradas ou triunfos". O início é fantástico e dá o tom do texto: “estas coisas são meros brinquedos que vêm entre observações sérias”. Considerando as representações teatrais luxuosas organizadas na corte, típicas dos séculos XVI e XVII e que tinham o nome de masques (cf. Houaiss \& Avery 6), Bacon se põe a analisar as danças, a roupa dos atores, a música e o modo acertado de cantar. Trivialidades, decerto, mas que revelam toda sua importância para uma compreensão acurada do poder: o "triunfo" 
posto no título dá o lado sério, contrabalança a brincadeira mostrando sua seriedade; o espetáculo é o espetáculo do poder, poder ornado, por assim dizer, que faz do baile uma demonstração de unidade, força e organização; em suma, um triunfo.

Saibamos apreciar essa capacidade analítica, que se faz possível justamente pelo caráter meticuloso dessa filosofia - digna aqui do Barthes das Mitologias falando de detergentes e saponáceos, do bife com fritas, da Volta da França. Longe de consistir num defeito, a frase classificatória meticulosa é expressão de uma observação rigorosa; o tipo de pensamento que lhe subjaz constitui a própria essência do procedimento teórico, primeiro, de uma ética baconiana, segundo, de toda a sua filosofia (pois não será demais repetir que o mesmo olhar agudo para os fatos e a capacidade de aprender com eles se encontra também nos textos da Instauração).

Bacon seria frio e calculista, pouco propenso à curiosidade genuína? Talvez o seja - mas como o florentino que ele tanto apreciava. Nesse caso, fazendo coro com Kiernan, tal como o Do avanço do saber elogia Maquiavel por ensinar "o que os homens fazem, não o que deveriam fazer" (Bacon 2, p. 245), poder-se-ia elogiar Bacon por ensinar os homens a investir toda a sabedoria no que eles querem ser, a alcançar seus fins e, sobretudo, por fornecer armas para um combate, a vida, em que o que importa é vencer . É bem a tarefa que Bacon assinala ao que ele chama de doutrina do avanço na vida (doctrina de ambitu vitae) ou faber fortunae: deve-se "ensinar aos homens a elevar-se e fazer fortuna" (Idem, p. 279). No fundo, esta é uma síntese de toda a filosofia de Bacon; a única peculiaridade dos Ensaios, ainda aqui, é nos dar a vê-lo com mais nitidez por meio de sua construção peculiar.

\section{Three notes on the relationship between Philosophy and textual form in the}

\section{Bacon's Essays}

Abstract: The aim of this article is to consider the philosophical relevance of the Francis Bacon's Essays, taking into account some aspects of its textual form: the unfinishing of the work, the change of its objectives and its classicatory constructions. Although at the first glance these aspects could suggest a theoretical weakness, indeed they express the elaboration of a new ideal of Philosophy.

Keywords: Bacon, The Essays, Philosophical Form.

\section{REFERÊNCIAS BIBLIOGRÁFICAS:}

1. BACON, F. Novum organum. Tradução e notas de José Aluysio Reis de Andrade. Col. Os Pensadores. São Paulo: Nova Cultural, 1988.

2. . O progresso do conhecimento. Tradução, apresentação e notas de Raul Fiker. São Paulo: Edunesp, 2007.

3. The Essayes or Counsels, Civill and Morall. Edited with introduction, notes, and commentary by Michel Kiernan. Oxford: Oxford University Press, 2000. Trad.: Ensaios de Francis Bacon. Tradução de Alan Neil Ditchfield. Petrópolis: Vozes, 2007.

4. . The Works of Francis Bacon. Collected and edited by J. Spedding, R. L. Ellis e D. D. Heath. Stuttgart: Friedrich Frommann, 1966, 14 v. (edição disponível em: http://gallica.bnf.fr/)

5. CASTELAIN, M. “Introduction”. In: BACON, F. Essais. Traduits, avec une introduction par Maurice Castelain. Paris: Aubier, 1979.

6. HOUAISS, A.; AVERY, C. B. Dicionário Exitus das línguas inglesa e portuguesa. Nova Jersey: Prentice-Hall, 1981.

7. KANT, I. Textos seletos. Tradução de Raimundo Vier e Floriano de Sousa Fernandes. Petrópolis: Vozes, 1985

8. KIERNAN, M. "General introduction". In: BACON, F. The Essayes or Counsels, Civill and Morall. Edited with introduction, notes, and commentary by Michel Kiernan. Oxford: Oxford University Press, 2000.

9. MELCHIONDA, M. Gli "Essayes" di Francis Bacon. Studio introduttivo, testo critico e commento. Florença: Olschki, 1979.

10. ROBERT, Pierre-Edmond. "Des manuscrits par milliers". Magazine littéraire, horssérie no 2 2, 40 trimestre de 2000 .

\section{NOTAS:}

1 - Frise-se que desde o XVII já se via na escrita baconiana uma fraqueza filosófica. Limitemo-nos a recordar o ajuizamento irônico de Harvey: Bacon é, sim, homem de "engenho e estilo" dignos de estima, não porém um "grande filósofo", pois "escreve filosofia como um lorde chanceler" (apud Spedding, Bacon 4, v. III, p. 515; grifo nosso). 2 - Quanto a este trabalho de reconstituição, ver Melchionda 9 e, sobretudo, a edição dos Ensaios por Michel Kiernan (Bacon 3).

3 - Por exemplo, o ensaio "Dos conselhos", da segunda edição, ganha um longo trecho 
na terceira que, a partir de casos contemporâneos, faz recomendações dignas de alguém que já passou pela chancelaria (o que não era o caso no momento da primeira redação). 4 - Hoje, normalmente as edições do livro trazem o fragmento de um 59o ensaio intitulado "Da fama"; ademais, o estudo de Melchionda 9 traz em apêndice fragmentos que possivelmente viriam a constituir novos ensaios.

5 - Seria o caso de ir além e afirmar ainda que a obra possui também uma vida própria que independe da vida do autor e, mesmo depois da morte deste, eventualmente lhe garante uma imortalidade ativa, que não é como a de uma estátua, inerte, mas que pode "engendrar e lançar infinitas ações e opiniões nas épocas sucessivas" (Bacon 2, p. 95).

Por sua vida própria, a obra pode responder por uma sorte de ideal laico de imortalidade ou eternidade.

6 - Como em uma dedicatória. No caso dos Ensaios, conhecemos quatro, uma para cada edição e uma que restou inédita. Estando no mundo, Bacon precisa da proteção dos grandes do mundo; como em todos seus trabalhos, é a eles que os Ensaios são dedicados, variando a direção, como o indica de Kiernan 8, conforme variam os interesses imediatos do autor. É exemplar o caso da dedicatória inédita, dirigida ao príncipe herdeiro Henrique, que porém morreu de repente no meio do preparo da segunda edição do livro; Bacon rapidamente a substituiu.

7 - Para tanto, é preciso considerar o repetido tratamento que o filósofo empreende do tema da ambição, em várias obras e destacadamente no Novo órganon (Bacon 1, I, 129). Ora, das ambições individuais à ambição de servir ao gênero humano, há graus, não descontinuidade.

8 - É impossível não mencionar a genial reversão do ideal grego de filosofia que Bacon promove no Do avanço do saber (Bacon 2, $240 \mathrm{seg}$.). Tendo em mente o Górgias, o filósofo fecha com o sofista e não com Sócrates; com o ideal ativo de melhora, progressão e resposta aos desejos humanos, em vez de um bem — o socrático-platônico — harmonioso e contemplativo, e que aos seus olhos redunda em estagnação e numa virtude que é "mais útil para aquietar perturbações do que para urdir desejos". Nesse sentido, se Bacon oferece uma filosofia para a vida, a filosofia tradicional só resta tornar-se um saber para a morte, "uma disciplina ou preparação para morrer".
O "privilégio do pensamento": um ensaio

de interpretação

Mariana de Gainza*

Resumo: Consideramos neste artigo uma forma particular da "batalha de idéias" que diferenciamos de outras formas de confrontação aberta, como a refutação. Trata-se de uma modalidade mais sutil, que procura incidir nos pesos relativos dos componentes teóricos de certas concepções. Associamos esta forma da produção teórica com a crítica materialista, o que nos permite conectar os esforços teóricos de Espinosa e de Marx, e também arriscar uma interpretação de uma tese polêmica - relativa ao privilégio do atributo pensamento - que Deleuze elabora na sua leitura da Ética.

Palavras-chave: crítica, materialismo, marxismo, entendimento infinito, estrutura

A filosofia, além de um espaço de diálogos e intercâmbios variados, pode ser considerada como um campo de batalha. Embora essa dimensão confrontadora que se apóia em uma disposição essencial do pensar filosófico - não receba hoje um reconhecimento universal, até não faz muito tempo a teoria era explicitamente considerada um espaço de lutas, pois a tendência estendida era a de aceitar que os discursos tinham, direta ou indiretamente, conseqüências. Noutros tempos, séculos atrás, além de concordar, os filósofos lutavam apaixonadamente entre si, com as armas teóricas de que dispunham, e de maneiras muito diferentes. Certas filosofias que, como a de Espinosa, por tomar bastante a sério a face subversiva da palavra suscitaram diversas tentativas de contestação teórica, servem especialmente para refletir sobre essa dimensão da crítica como refutação ou impugnação, uma das formas do combate filosófico: ela pode ser total ou parcial quanto aos conteúdos, externa ou interna segundo a posição do refutador em relação ao objeto; pode pretender subordinar ou absorver o ponto de vista do adversário, ou tentar destruir por completo suas razões; pode ser mais ou menos explícita, mais ou menos agressiva, mais ambígua ou mais decidida. E claro, pode ser efetiva, ou impotente, e até produzir os efeitos contrários aos perseguidos pelo crítico.

Mas além das refutações, existem outras formas de confrontação filosófica.

* Doutoranda do Departamento de Filosofia da USP e bolsista da Fapesp. 